\title{
$\underline{3}$ \\ Mapping the Gendered Terrain
}

Women and men occupy different and unequal economic and social positions and roles; they undertake different activities, face different constraints and accordingly make different choices (Sharp, 1999). In order to understand what the implications of different types of revenue generation are on women and men, it is important to analyse the dynamics of unequal gender relations in the economic sphere.

\section{Gender and work}

The economy is a gendered structure with two distinct yet inter-related sectors: the market and the (unpaid) care economy. The unpaid care economy involves work such as: cooking; cleaning; taking care of the young, the sick and the old; fetching water; and collecting fuel wood. Work in the care economy underpins the market economy. Women carry out the reproductive and nurturing functions that maintain and sustain the labour force. Most of the work in the care economy is done by women, and government revenue generation measures such as user fees in government health facilities and privatisation of service delivery have greater implications for them than for men.

An analysis of the market economy reveals gender differences. Women face various inequities in the labour market including occupational segregation in low-paying jobs and contingent work and the 'glass ceiling' in professional employment. In 2003, 51 per cent of employed women earned USh40,000 per month or less, compared to 44 per cent of employed men. As regards underemployment (working on economic activities for less than 40 hours a week), 75 per cent of the women compared to 55 per cent of the men fell into this category. The 2006 Demographic and Health Survey reports that 'Men are more likely to be paid in cash (34 per cent) for their work than women (19 per cent). Women are more likely to work but not receive payment (30 per cent) compared with men (13 per cent)' (Uganda Bureau of Statistics, 2006).

Eighty-one per cent of women and 94 per cent of men are employed. Among women who are currently employed, 75 per cent are engaged in agriculture. The percentage for men is 69 per cent. More men ( 5 per cent) than women ( 3 per cent) are likely to be employed in the professional, technical and managerial occupations that require more skills and have higher income-earning potential (see Table 3.1).

Most work in the subsistence and care economy is undertaken using unskilled labour and without the benefit of energy- or labour-saving technology, suggesting that the returns on women's labour are minimal. Most Ugandans do not earn a living wage, and thus production for own consumption and work in the care economy is critical in subsidising household income. 
Table 3.1. Gendered distribution of work by occupation

\begin{tabular}{lrr}
\hline Occupation & F & M \\
\hline Professional/technical/management & 3.3 & 4.8 \\
Clerical & 0.4 & 0.3 \\
Sales and services & 13.2 & 10.0 \\
Skilled manual & 5.1 & 11.1 \\
Unskilled manual & 0.7 & 4.3 \\
Domestic service & 1.6 & 0.1 \\
Agriculture & 75.4 & 68.6 \\
Not available & 0.3 & 0.6 \\
\hline
\end{tabular}

Source: Uganda Bureau of Statistics, 2006

More women than men face trade-offs because of time poverty. Due to their work in the care economy, women cannot easily transfer their labour and reallocate their time between different activities. The gender-based assignment of household roles restricts the substitution of male and female labour time (Bakker, 1994). This imposes a 'reproductive labour tax', which is a kind of tithe levied against women's unpaid work in the care economy that distorts their ability to engage in income-generating activities (Palmer, 1991).

The lower relative earning power of women and their predominance in informal employment mean that they are unlikely to bear the brunt of the direct tax burden. However, because their purchasing power is limited, they are likely to experience a heavier burden of indirect taxes.

\section{Gendered distribution of resources}

Uganda is an agro-based economy and land is the key resource on which the majority of rural women and men draw to secure their livelihood. In urban areas, access to employment and credit are key for survival. The ability to work is also important, as noted by a men's focus group in Wakiso District: 'The key resource we have in this community is labour. If you do not work, you cannot survive.'

A 2003 gender analysis of the Ugandan national household surveys (1992-2003) showed gender inequality in access to and control over a range of productive, human and social resources (Lawson, 2003). It showed that female-headed households have particularly low asset levels and that there are significant gender differences relating to land owned and cultivated. Although women are largely responsible for agricultural production, their land ownership is mainly limited to usufruct rights. Available statistics indicate that women own only 7 per cent of the registered land and that only 16 per cent of women, mostly in urban areas, own registered land. In rural areas, ownership of land is still embedded in culture, as emerged in a focus group with men in Iganga: 'Yes, a few women have bought land. But such a woman ceases to be a woman, she becomes a man!' 
Men tend to have control over money and income from sales of agricultural production, even though it is the women who grow the crops (MoFPED, 2002).

Whereas gender gaps in education are being closed, disparities still persist as reflected in the female adult literacy rates of 69 per cent compared to the male rate of 79 per cent found in the 2002/2003 Uganda National Household Survey (Uganda Bureau of Statistics, 2003). This implies that women continue to have limited opportunities to diversify their economic base into sectors with higher returns than agriculture. There is also significant gender inequality in gaining access to credit (Klasen, 2004). More men than women are successful in credit applications and women normally receive smaller amounts. Women generally benefit more from community cooperatives and loans. The implication of this is that it constrains a shift by women from small to medium and largescale enterprises.

\section{Decision-making, production and consumption patterns}

Men dominate decision-making, whether with respect to the household, agricultural production, labour allocation, consumption or participation in the labour force. Women's limited decision-making power is associated with their insecurity of access to productive resources, especially land. For instance, although as noted earlier women perform most of the agricultural work, they do not make decisions about what enterprises to get involved in and how the benefits accruing from them are distributed. According to the Uganda Demographic and Health Survey (Uganda Bureau of Statistics, 2001), 40 per cent of women employed for cash participate in household decision-making. This is in comparison with 22 per cent of women not employed for cash and 14 per cent of unemployed women. Women's inadequate participation in household decision-making constrains their economic opportunities and choices.

Women and men's consumption patterns are different. The 2003 gender analysis of national household surveys showed that male-headed households spend disproportionately large amounts of household expenditure on alcohol, while female-headed households spend high proportions on school fees (Lawson, 2003). This implies that taxation on alcohol affects disproportionately more men than women. Cost sharing in education, on the other hand, is likely to reduce women's more than men's disposable income.

Box 3.1 presents some community perspectives on consumption and decisionmaking patterns. 


\section{Box 3.1. Community perspectives on consumption and decision- making}

\section{Women's focus group, Wakiso}

Men are considered to be the household heads. The presumption is that they take care of the family needs, but the reality is different. Men are no longer responsible. Nowadays, women shoulder the financial burden. It is no longer just a work burden. A woman in the village has to work very hard in order to get money for paying (secondary) school fees to support her children.

\section{Men's focus group, Wakiso}

We spend our money on things that are expensive to maintain. Phones consume a lot of money and yet almost everybody here owns one.

\section{Women's focus group, Iganga}

It is our chairman and the businesspeople who have personal phones. We use the village public phone to make emergency calls. We call if we have lost somebody, sometimes when we are looking for markets for our produce or trying to compare the price of commodities with colleagues and friends in other places. Also, when we have a sick child, we can easily communicate with our husbands. Men, on the other hand, use the phone for business and also to get in touch with their lovers.

\section{Men's focus group, Iganga}

The man is in charge of the 'steering' [wheel]. He makes all household decisions. In some homes, though, the men consult the women. 